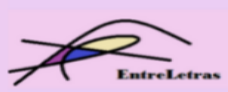

REVISTA ENTRELETRAS (ARAGUAÍNA), V. 12, N. 3, SET./DEZ. 2021 (ISSN 2179-3948 - ONLINE)

\title{
EL ENUNCIADO DE/SOBRE LA VIOLENCIA EN LA NOCHE DE TLATELOLCO, DE ELENA PONIATOWSKA
}

\section{O ENUNCIADO DE/SOBRE A VIOLÊNCIA EM LA NOCHE DE TLATELOLCO, DE ELENA PONIATOWSKA}

DOI 10.20873/uft2179-3948.2021v12n3p91-103

Mercedes Magdalena Rodríguez ${ }^{1}$

\begin{abstract}
Resumen: En nuestro trabajo abordamos el volumen La noche de Tlatelco (1971) y efectuamos una propuesta de análisis. Ésta se centra en las representaciones de la violencia advertidas en el relato testimonial a partir del desenlace trágico que silencia el Movimiento Estudiantil de 1968 en México. Adoptando una perspectiva foucaultiana, indagamos la constitución del enunciado que articula redes de representaciones simbólicas sobre ese acontecimiento. Y, destacando la imposibilidad de una relación transparente en los mecanismos de la memoria, situamos la lectura entre los pliegues de lo intertextual a fin de interceptar el proceso de mediación/traducción sobre los desplazamientos de la experiencia traumática.
\end{abstract}

Palabras clave: La noche de Tlatelolco; Violencia; Testimonio; Enunciado; Pos-memoria

Resumo: Em nosso trabalho abordamos o volume La noche de Tlatelolco (1971) e efetuamos uma proposta de análise que coloca em enfoco as representações da violência observadas no relato testimonial a partir do trágico desenlace que silenciou o Movimento Estudantil de 1968 no México. Adotando uma perspectiva foucaultiana, indagamos a constituição do enunciado que articula redes de representações simbólicas sobre aquele acontecimento. E, ressaltando a impossibilidade de uma relação transparente nos mecanismos da memória, situamos a leitura entre as dobras do eixo intertextual para interceptar o processo de mediação/tradução sobre os deslocamentos da experiência traumática.

Palavras-chave: La noche de Tlatelolco; Violencia; Testemunho; Enunciado; Pos-memória

\section{Introducción}

La noche de Tlatelolco [1971] (en adelante LnT) comprende un volumen de testimonios que reconstruyen el Movimiento Estudiantil del 68 en México, pero, particularmente, la noche del 2 de octubre en que se despliega un amplio aparato de represión. La concentración convocada en la Plaza de las Tres Culturas del D.F. por los líderes estudiantiles termina en un

\footnotetext{
${ }^{1}$ Doctoranda PPGEL-Universidade Estadual de Feira de Santana (Bolsista Capes), magmerce@hotmail.com ORCID ID: https://orcid.org/0000-0001-7403-5159
} 


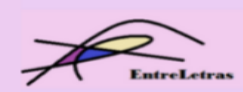

REVISTA ENTRELETRAS (ARAGUAÍNA), V. 12, N. 3, SET./DEZ. 2021 (ISSN 2179-3948 - ONLINE)

acontecimiento marcante que conmueve al país y se transforma en uno de los episodios más sangrientos de la historia mexicana. ${ }^{2}$

En el presente trabajo situamos las representaciones de la violencia en la línea testimonial. A tal efecto, y adoptando en el análisis una perspectiva foucaultiana, indagamos la constitución del enunciado - que articula las redes de memoria sobre el acontecimiento - a partir de la siguiente premisa: el enunciado "no es en sí mismo una unidad, sino una función que cruza un dominio de estructuras y de unidades posibles y que las hace aparecer, con contenidos concretos, en el tiempo y en el espacio (FOUCAULT, 2002, p. 145). Como función y elemento de análisis, este enunciado se moviliza - postulamos - entre el binomio verdad/posmemoria que emplaza, a partir del archivo de los testimonios, la responsabilidad del Estado en el ejercicio de la violencia represiva. Para contextualizar la serie testimonial, recordemos que durante la década del 70 se produce una erosión del objeto literario, situación que convive con el auge de los estudios de la memoria en las ciencias sociales y las humanidades. En esto contribuyen las críticas al canon y el cuestionamiento de la noción sacralizada de la literatura (FABER, 2014). En este punto, los aportes de Foucault (1992, p. 189) nuevamente nos permiten circunscribir el análisis:

Por "verdad", entender un conjunto de procedimientos reglamentados por la producción, la ley, la repartición, la puesta en circulación, y el funcionamiento de los enunciados. La "verdad" está ligada circularmente a los sistemas de poder que la producen y la mantienen, y a los efectos de poder que induce y que la acompañan.

Por consiguiente, siendo el enunciado de/sobre los traumas de la violencia el que articula el discurso en el interior del archivo testimonial - siempre abierto y disperso -, interceptamos este proceso histórico en las regularidades que es posible advertir si observamos lo discontinuo y fragmentario de dicho archivo. En relación con los mandatos y patrones que se gestionan en torno al silencio, las elaboraciones estéticas sobre el trauma - como modo de representar el devenir sobre la herida en la memoria - “generalmente abarcaban los géneros más 'disidentes', como literatura testimonial, documentales o novelas autobiográficas" (GENSCHOWSPILLER, 2017, p. 12). ${ }^{3}$ Así, el devenir de los sucesos - previos y posteriores a la sangrienta

\footnotetext{
${ }^{2}$ Para determinar los rasgos fundamentales de esta exploración testimonial en América Latina, seguimos a López Badano y Cums Yumar cuando señalan que "en la investigación literaria contemporánea el corpus integrado por representaciones simbólicas de la memoria histórica traumática ocupa un lugar preponderante en países que han padecido dictaduras o poderes autoritarios" (2021, p. 121).

${ }^{3}$ Por su parte, Samuel O’Donoghue pone en foco la transferencia de autoridad testimonial para revisar la relación conflictiva de la posmemoria - concepto acuñado por Marianne Hirsch en 1992 - con la teoría del trauma,
} 


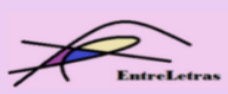

REVISTA ENTRELETRAS (ARAGUAÍNA), V. 12, N. 3, SET./DEZ. 2021 (ISSN 2179-3948 - ONLINE)

noche de Tlatelolco - vuelve una y otra vez sobre las redes de la memoria. Al respecto, tengamos en cuenta que la noción de discontinuidad, como uno de los elementos fundamentales del análisis del discurso,

(...) lo que busca describir son los límites de un proceso, el punto de inflexión de una curva, la inversión de un movimiento regulador, los límites de una oscilación, el umbral de un funcionamiento, la emergencia de un mecanismo, el instante de desorden de una causalidad circular. (FOUCAULT, 1993, p. 90)

En el relato/enunciado es posible advertir que la formación discursiva se manifiesta a través de dos vectores: el primero está conformado por la red de memorias traumáticas, las versiones - oficiales y contraoficiales - y las representaciones sobre la violencia que ha desencadenado la masacre durante la movilización del 2 de octubre concentrada en la plaza central de la capital mexicana; y el segundo, en contrapartida, por el conjunto que determina la emergencia de sentidos que se movilizan cuando deshilvanamos la trama del enunciado/relato. En esa doble matriz se inscribe la historia oral dejando testimonios atravesados por cierto régimen de verdad. En este punto - recordemos - para Foucault son tres los grandes sistemas de exclusión que afectan al discurso: "la palabra prohibida, la separación de la locura y la voluntad de verdad" (2005, p. 23). Por ello, vinculado con el relato sobre la violencia construido en el volumen y puesta en consideración la capacidad del lenguaje para enunciar la verdad de los acontecimientos - en el sentido de transparencia y transmisibilidad $-{ }^{4}$ en este trabajo proponemos una lectura crítica que aborda la siguiente cuestión: ¿qué sucede con la palabra que dice, revela y denuncia - cuando se acerca a la violencia extrema que ratifican las formas testimoniales de los sobrevivientes de la masacre? Y, en ese sentido, ¿cómo trabaja el enunciado literario en relación con dichas formas? Según nuestra hipótesis de lectura, se trata de una palabra - léase: forma del lenguaje vinculada con la historia oral - en la que la periodista y escritora Elena Poniatowska inscribe su volumen desde el subtítulo. Esa marcación va dejando coordenadas sobre cómo descifrar la palabra en su instancia dialógica de conversación reconstruida desde lo fragmentario.

consolidada durante los años noventa en los estudios sobre el Holocausto. Señala que, basada en un modo de dar legitimidad al testimonio de los supervivientes, dicha teoría "instó a que se dejaran a un lado los criterios de fiabilidad y fidelidad; para los teóricos del trauma, el testimonio no era una fuente histórica cualquiera sino un sistema alternativo para conocer un pasado atormentador" $(2019$, p. 8$)$.

\footnotetext{
${ }^{4}$ Nuestro análisis sobre la construcción del volumen entronca, en líneas generales, con lo expresado por Teresa
} Basile (2015) en el Prefacio al volumen Literatura y violencia en la narrativa latinoamericana reciente. 


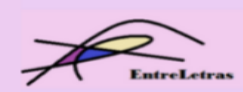

REVISTA ENTRELETRAS (ARAGUAÍNA), V. 12, N. 3, SET./DEZ. 2021 (ISSN 2179-3948 - ONLINE)

\section{Método}

El trabajo comprende, en primer lugar, el análisis de los testimonios que integran el volumen para luego clasificarlos a partir del recorte establecido: los traumas de la violencia. Partiendo de la línea testimonial, organizamos el material conformado por distintas versiones sobre los acontecimientos. Por esto, situamos el género discursivo - como transición entre la literatura y el periodismo - y analizamos tanto los mecanismos de representación como la tarea del montaje periodístico que contribuye en la disposición de los testimonios como polifonía de voces. En tanto plano de análisis, abordamos el discurso siguiendo el prisma foucaultiano a fin de problematizar en el corpus testimonial la noción de enunciado (La arqueología del saber). A la luz de este enfoque, también examinamos la noción de discontinuidad para determinar la irrupción del acontecimiento en el discurso que emplaza el trauma de la coerción (El discurso del poder) y los regímenes de verdad asociados al enunciado de/sobre la violencia (Microfísica del poder).

\section{El corpus: descripción}

Cabe consignar que los testimonios compaginados fueron recogidos entre octubre y noviembre del 68, y que los testimonios de los estudiantes presos se obtuvieron entre el 68 y el 70, según lo aclara Poniatowska en la segunda parte del volumen. Por lo que no constituye un dato menor que la primera edición se presentó a la consideración pública a sólo tres años de ocurridos los acontecimientos. Allí se registran segmentos de textos que hemos agrupado en crónicas, declaraciones e informes, fragmentos de reportajes, diálogos, manifiestos y citas. Respecto a las fuentes periodísticas empleadas en la $L n T$, observamos, por un lado, que el compilado de la información surge de un trabajo de confrontación entre las versiones y los titulares de la prensa nacional (El Día, Excélsior, Revista de la Universidad, La Prensa, Siempre!, El Universal, El Heraldo, Diario de la tarde, Ovaciones, El Nacional, El Heraldo de México, Novedades y El sol de México). Por otro lado, en la organización de dichas fuentes sobresale la inscripción del seguimiento efectuado por el periodismo internacional (Le Fígaro, Le Nouvel observateur y The Guardián). Como planos en superposición, lo testimonial y lo documental se abren paso entre la estrategia discursiva de la repetición dada en las pancartas, las citas del Che en los carteles, los letreros, las voces inscritas en la intermitencia y las canciones estudiantiles. Gravitan también en este eje las cartas, las actas policiales, los comunicados de prensa, los fragmentos de reportajes, los segmentos de conversaciones, 


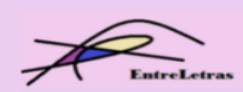

REVISTA ENTRELETRAS (ARAGUAÍNA), V. 12, N. 3, SET./DEZ. 2021 (ISSN 2179-3948 - ONLINE)

incluidas las declaraciones públicas y jurídicas, los volantes, los poemas, los encabezados de periódicos y los discursos de los líderes estudiantiles en los actos públicos.

En cuanto a las variables de las fuentes empleadas, encontramos extractos de crónicas, declaraciones ante medios los gráficos y audiovisuales, segmentos del IV Informe Presidencial al Congreso, conversaciones grabadas y la convocatoria pública del Rector de la UNAM. Asimismo, es posible seguir las instancias conflictivas del debate televisivo en la serie "Los narradores ante el público" en diálogo con las increpaciones de los oficiales a los estudiantes, las solicitadas publicadas en los periódicos y los desplegados difundidos por el denominado Consejo Nacional de Huelga. A lo anterior se suma el emplazamiento de distintas posturas entre los intelectuales de la época generadas a partir de la lectura de un volante en la serie "Los narradores". Se trata de posiciones que se contextualizan entre los corridos populares, el texto de renuncia del Rector, los comentarios no individualizados, la reproducción de conversaciones, una carta de Armenia y un “Mensaje de Navidad, 1969”, transmitido por radio.

\section{Desarrollo}

\subsection{Relatar la violencia}

Para empezar, debemos señalar que las coordenadas en la línea testimonial se manifiestan como puentes que comunican los significados asociados al trauma, a la memoria escindida y a lo indecible cifrado en el desencadenamiento de los sucesos. La lengua colapsa luego del suceso límite que deja el 2 de octubre. Desgarrada, inicia la búsqueda de un lenguaje capaz de reconstituirla, de rescatarla de ese lugar de silencio que es el trauma. Así es como, a modo de ensayo que traduce la desazón frente a lo inexplicable, esa lengua se desarticula y se mueve en el vacío. Tornándose una palabra balbuceante en relación con las formas del testimonio, conforma un procedimiento intermitente en donde la linealidad progresiva y razonante de la narración se extravía en los avatares de la voz colectiva que intenta reconstruir el acontecimiento. En este punto, con Foucault destacamos que "[e]1 problema específico del análisis del discurso podría formularse así: ¿cuál es, pues, esta irregular existencia que sale a luz a en lo que se dice y no en cualquier otra parte?" (1993, p. 98). Intercambiando los términos, podríamos pensar que el trauma es esa "irregular existencia" que el relato/enunciado intenta eludir porque es el momento en que se produce la masacre, y lo hace manejando los tiempos de la narración. Como queriendo conjurar la violencia, la acecha con el discurso que se rearma desde la voz contraoficial. Por lo tanto, es en esta forma de resolución donde el mecanismo de 


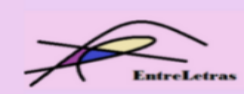

REVISTA ENTRELETRAS (ARAGUAÍNA), V. 12, N. 3, SET./DEZ. 2021 (ISSN 2179-3948 - ONLINE)

la ficción entra en contacto con el testimonio y lo regula con su poder de confrontación, incluso utilizando como instrumento al relato/enunciado que concatena voces.

Cuando a través de la transferencia liberadora de este relato/enunciado alineal el testimonio se vacía de su carga de memoria-verdad, triunfa el mecanismo del discurso asociado a la ficcionalización de las formas testimoniales. Construido a partir de la representación del (no)lugar que territorializa la verdad de las víctimas, dicho mecanismo comprende la inflexión del discurso ficcional donde la masacre, como signo, ingresa por partida doble en el relato: como hecho político-social y como acontecimiento representado en su devenir. Pero más trascendente aún es que la escritura, posicionada en alguna encrucijada del discurso de Poniatowska, revierte los acontecimientos y los funda nuevamente para conjurar la muerte, es decir, construye ese (no)lugar -como zona franca de la historia- en donde la masacre nunca ocurrirá: "[los muchachos] son muchos, vienen hacia mí con sus manos que levantan la pancarta, manos aniñadas porque la muerte aniña las manos; todos vienen en fila apretadas, felices, andan felices, pálidos, sí, y un poco borroneados, pero felices...” (p. 13). Precisamente allí, en el dominio del signo bifronte que mira el pasado inmediato y lo representa como futuro que no debería acontecer, es donde - proponemos- se puede reconstruir la voz testimonial de las víctimas. Este mecanismo del discurso hace posible que se neutralice el acontecimiento, y con él su impacto. En esta dirección oblicua del enunciado que relata desde el presente imposible y fricciona la línea temporal del pasado en el eje de un futuro redimido -donde nunca ocurrirá la masacre-, observamos que las voces de los sobrevivientes modulan un saber político-social del acontecimiento desde múltiples variables de interacción vinculadas con el hecho todavía no procesado como duelo. Así, coincidencia, confrontación, desolación, desazón, reivindicación, consolación, resistencia y persistencia en la lucha son algunas de sus variables. Como nudos que restituyen la memoria de los que han sido silenciados por la violencia, las formas del relato conversacional rearman - desde el plano de la ficción - el testimonio colectivo de los que ya no tendrán memoria ni voz: las víctimas que han perecido en la Plaza de las Tres Culturas. En este espacio de restitución de una forma de verdad respecto de lo que ha sido negado con la muerte y silenciado con la desaparición, el acontecimiento instalado en la línea del futuro volverá una y otra vez sobre la pos-memoria. Nunca terminará de pasar porque el relato/enunciado lo instala con insistencia como acontecimiento gravitando en el eje conversacional que construye la ficción, aquel que se retroalimenta cíclicamente de la suma de voces. Dado este punto, planteamos lo siguiente: la materialidad de las voces comprende zonas del relato que emergen como lugares de refugio. Y en este sentido, el enunciado - con su 


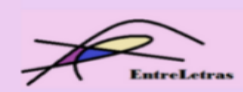

REVISTA ENTRELETRAS (ARAGUAÍNA), V. 12, N. 3, SET./DEZ. 2021 (ISSN 2179-3948 - ONLINE)

narratividad y el complejo de literatura nómade que lo alienta - no está simplemente traduciendo y reflejando voces, versiones y contextos. Con mayor exactitud, podemos pensar que este enunciado les atribuye una realidad: los construye.

De esta manera, la línea del presente comprende la constelación de voces que reconstruyen la memoria, donde el pasado es el espacio del acontecimiento y de la memoria fragmentada; y futuro, el devenir de la reparación histórica. En esa fricción de temporalidades, la masacre nunca ocurrió y el Movimiento Estudiantil vuelve a gestarse joven y desbordante de algarabía: “(...) ya no hay muros de bayonetas que los rechacen violentamente, ya no hay violencia (...) vienen a pie, vienen riendo, son muchos, vienen con esa loca alegría que se siente al caminar juntos en esta calle, nuestra calle, rumbo al zócalo" (PONIATOWSKA, p. 14). De esta forma, observamos que el relato fluctúa en tres vertientes que indagan sobre el trauma y se fortalecen progresivamente en su condición de temporalidad. "No hay que remitir al discurso a la lejana presencia del origen; hay que tratarlo en el juego de su instancia”, dice Foucault (1993, p. 96) para advertir que es necesario aprehender cada modulación del discurso en su irrupción de acontecimiento y bajo su dispersión temporal. En contrapartida, la lengua queda retraída en un trayecto inverso: ensimismándose en cada punto traumático, colapsa frente al suceso límite y se niega a nombrarlo. Situado en este punto, el enunciado gana en espesor respecto de la intervención ficcional que establece la circulación de voces narradoras. Y esto porque está asociado

(...) a una "referencia" que no está constituida por "cosas", por "hechos", por "realidades", o por "seres", sino por leyes de posibilidad, reglas de existencia para los objetos que en él se encuentran nombrados, designados o descritos, para las relaciones que en él se encuentran afirmadas o negadas. (FOUCAULT, p. 148)

Es así como la lengua dañada por el trauma le hace frente tanto al suceso histórico - que ha impactado contra la subjetividad social - como al lenguaje que se ha detenido en la producción de sentidos. Por lo tanto, las formas del relato/enunciado, que testimonian de un modo intermitente, dominan el vértigo interno del lenguaje para reencauzarlo sobre la zona del silencio reparador. Respecto de la violencia, en el volumen se establece un territorio de exploración de múltiples coordenadas, a saber: la escritura sesgada por el suceso histórico reciente, la lengua asociada a un decir traumático, y el lenguaje de representación tensionado entre la dinámica del decir y el silencio.

3.2 Lejos está aún el tiempo de convertir la sangre en piedra de memoria 


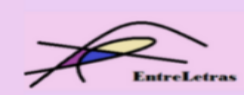

REVISTA ENTRELETRAS (ARAGUAÍNA), V. 12, N. 3, SET./DEZ. 2021 (ISSN 2179-3948 - ONLINE)

La construcción del relato/enunciado en $\operatorname{LnT}$ no sana el trauma, sólo lo aproxima al espacio de la escritura para interrogarlo con las formas propias de la narración. Más aún, no sólo le niega a la obra que indaga en la historia oral la transferencia liberadora para suturar las heridas del trauma, también invalida toda reparación posible en el futuro inmediato. Es así como, desde el férreo proceso de ficcionalización, la escritura literaria profundiza el estado de conmoción a través de las voces narradoras que conversan sus memorias y se interpelan constantemente. Dicho con mayor precisión: donde el montaje periodístico encuentra sus límites, la literatura reencauza la toma de conocimiento respecto de la masacre y la presenta como el resultado de un plan de inteligencia llevado a cabo por el Estado. Así, en su travesía por las voces, el relato/enunciado inicia la búsqueda de la verdad, esto es: los responsables políticos y materiales del hecho. La escritura ficcional se despoja de los condicionantes que restringen el marco de acción del plano periodístico. El cual, claro está, en más de un punto encuentra sus límites y se torna insuficiente para indagar los porqués entramados secretamente en el suceso. Fuera de las imposiciones relacionadas con la estabilidad del significado, la linealidad progresiva y la coherencia vehemente de la narración, el relato se libera del memorial Tlatelolco y exacerba la imagen de la sangre derramada.

Perturbadora e insistente, la imagen de la masacre que reconstruyen las voces se instala en el relato/enunciado para contrarrestar la versión oficial. De ahí que la noción de "emboscada" adquiera en y por ese relato el valor de una intermitencia sobre el nudo traumático que ha dejado el acto de violencia extrema, donde el único responsable es el Estado mexicano. Por tal motivo, y llegado a este punto, el panóptico literario posibilita eludir el silencio paralizante para transformar la voz colectiva en un relato de urgencia respecto de la construcción de la verdad. Porque si en un primer intento la palabra, la poesía, el relato y la ficción pugnan contra lo indecible, luego sitúan el suceso y lo acechan - desde el límite de la violencia - a partir de una lengua desgarrada que balbucea y deriva en el silencio. Esto determina que el ingreso de la línea testimonial provoque una inflexión decisiva en la escritura. La aparición de las voces - que debaten a favor de la construcción de la verdad - activa la producción de significados y saca a la palabra del plano de negación para instalarla en el dominio de la autoridad-legitimación. Así, el relato/enunciado comprende un principio donde se produce el proceso de materialización de la voz: oralidad, testimonio, narradores, formas de narrar, formatos y conversación. Parte de ese principio comprende la inscripción de dicha materialidad en un proceso que no es sólo literario (esto es: ficcionalizado) ya que se trata también de un procedimiento que incluye la forma de hablar del otro. De modo tal que el habla del que es vulnerado por el sistema político- 


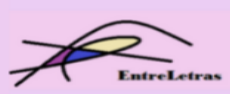

REVISTA ENTRELETRAS (ARAGUAÍNA), V. 12, N. 3, SET./DEZ. 2021 (ISSN 2179-3948 - ONLINE)

institucional emerge en la construcción del relato de vida como otro formato textual que permite sostener la interpelación en el foro público en que se transforma el volumen de Poniatowska. Allí es donde modulan las voces en una conversación de alcance comunitario, cuya atmósfera se transforma en el lugar más seguro para construir la ficción.

Como zona de refugio, y de ejercicio marginal del poder, la ficción es una operatoria del discurso que socava la versión oficial del Estado. Contradiciéndolo y tensionándolo hasta el límite, logra construir, así, una zona de aproximación a la verdad. Por lo tanto, no hay sutura ni reparación de la memoria colectiva. Por el contrario, a través del mecanismo de ficción que permite recrear las escenas del Movimiento Estudiantil en sus distintas facetas, se expande la grieta en la memoria que torna visible a los sobrevivientes y a las víctimas. Lacerando aún más la herida, el impacto de la masacre detona una y otra vez sobre la retina de la mirada colectiva, y también en nuestra visión de lectura. La llegada de las voces al foro público que comprende el volumen hace que no se clausure el acontecimiento histórico en ninguna de sus instancias, aunque duela, porque para mitigar el trauma de la herida está el poema de Rosario Castellanos. Entramado junto a las voces que se debaten en la esfera político-discursiva en que se constituye el volumen, este poema se reviste de un decir cívico que intenta conjurar el dolor. La poesía entonces, como palabra unidireccional, llega al plano de la escritura con una verdad clausurada, ya histórica, e inmodificable en su devenir. Allí no existe la memoria falible, allí todo ocurre tal cual sucedió. El acontecimiento en el gesto poético es palabra a medio decir: se expone con todos sus blancos y vacíos, con la desazón de la verdad. Se clausura en el pasado. Allí la masacre se cierra como herida sin ser redimida por la verdad que busca fisurar las redes del poder. Es donde la palabra despojada se aleja del ropaje ficcional y se deja conducir hacia la memoria petrificada. Imposibilitada de avanzar hacia la verdad de los hechos, lejos permanece, entonces, de los formatos de la entrevista y del tono azorado de la conversación, del testimonio y del marco ficcional que lo recorta y lo direcciona hacia el terreno de la palabra sublevada.

La forma testimonial oblicua no alcanza a la palabra poética porque ésta es un espacio autónomo donde se expresa el dolor y la pérdida dentro de la escritura. En cambio, la forma testimonial comprende un espacio de exilio donde la palabra silenciada por el trauma se libera en un decir diferido, pero contestatario a la vez en relación con el constructo pos-memoria que comienza a gestarse en el ámbito oficial al día siguiente de la masacre. Como fenómeno sociocultural, histórico y político ligado al ejercicio del poder, en ese constructo los sujetos se evidencian atrapados por mecanismos de persuasión, en lo que contribuye el periodismo asociado al poder del presidente Echeverría. En la segunda parte de $L n T$ aparece la imagen del 


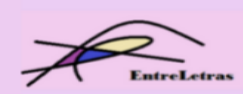

REVISTA ENTRELETRAS (ARAGUAÍNA), V. 12, N. 3, SET./DEZ. 2021 (ISSN 2179-3948 - ONLINE)

sujeto recopilador de voces que trabaja con los resortes internos de una palabra-versión, la cual solicita tomar estado público. Además de referirse a la fórmula del testimonio como material que se modula en diferentes contextos, Poniatowska resume los vaivenes de dicha palabra en un proceso de restitución. Desde ese lugar de inscripción, la versión es presentada en la trama del relato como instancia de restitución pública que resignifica la voz de la protesta social entre los ecos de las voces de las víctimas y los sobrevivientes, pero también en el silencio frente a la imposibilidad de articular verbalmente la imagen intraducible del miedo:

Este relato les pertenece. Está hecho con sus palabras, sus luchas, sus errores, su dolor y su asombro. Aparecen también sus 'aceleradas', su ingenuidad, su confianza... Aquí está el eco del grito de los que murieron y el grito de los que quedaron. Aquí están su indignación y su protesta. Es el grito mudo que se atoró en miles de gargantas, en miles de ojos desorbitados por el espanto el 2 de octubre de 1968, en la noche de Tlatelolco. (p. 164)

Para ser más precisos, la mención de esta cifra social que posee el relato es la que explicita un trabajo formal con la confrontación de versiones y la reconstrucción de contextos. De esta forma, la suma de procedimientos sobre los distintos formatos del testimonio, se impone frente al vacío de la evidencia fotográfica. Este principio técnico determina que la recopiladora apuntale, sobre la práctica del montaje, la visión fracturada de una imagen inexistente, aquella que los medios gráficos del momento no pudieron captar. En efecto, la siguiente aclaración de Poniawtoska se refiere a la ausencia de la prueba material: "Los cuerpos de las víctimas que quedaron en la Plaza de las Tres Culturas no pudieron ser fotografiados debido a que los elementos del ejército lo impidieron" (p. 164). Sin dudas, es la falta de certeza respecto del número de víctimas el punto de inflexión que refuerza la reconstrucción de versiones. Provenientes de las imprecisiones del periódico nacional La Prensa, del manifiesto que publicó el denominado Consejo Nacional de Huelga al día siguiente y del número estimado por el diario inglés The Guardian, las versiones vuelven una y otra vez sobre la inexistencia de la imagen. Por ello, la pervivencia de una zona indeterminada, sostenida también en las divergencias de las versiones de los detenidos y heridos, determina un vacío en el montaje fotográfico, en donde la explosión del acontecimiento se mide únicamente por las secuencias de imágenes previas y posteriores al 2 de octubre. En tal sentido, el montaje - tanto del archivo fotográfico que se incluye en el volumen como de las versiones que intentan completarlo - se sostiene en dos certezas que enuncia la autora/mediadora: la imprecisión en el número de víctimas que dejó la masacre y la incertidumbre frente a la lógica de los acontecimientos que determinó la represión: 


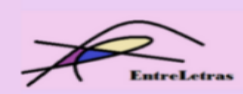

Posiblemente nunca sepamos cuál fue el mecanismo interno que desencadenó la masacre de Tlatelolco... La noche triste de Tlatelolco -a pesar de todas sus voces y testimonios- sigue siendo incomprensible. ¿Por qué? Tlatelolco es incoherente, contradictorio. Pero la muerte no lo es. Ninguna crónica nos da una visión de conjunto. (p. 170)

De modo que la condición icónico-discursiva del volumen La noche de Tlatelolco se construye con la incorporación de un archivo fotográfico y a través de la disposición gráfica de las versiones sobre los hechos, en segmentos que reconstruye la pluralidad del discurso social entre los blancos de un no decir oficial. Se descubre así el artificio de montaje de las fuentes empleadas. Planteado en relación con las condiciones que rigen, "en un momento dado y en una sociedad determinada, la aparición de los enunciados", Foucault (1993, p. 100) denomina archivo

(...) al juego de las reglas que determinan en una cultura la aparición y la desaparición de los enunciados, su remanencia y su eclipse, su existencia paradójica de acontecimientos y de cosas. Analizar los hechos del discurso en el elemento general del archivo es considerarlos, no como documentos (de una significación oculta, o de una regla de construcción), sino como monumentos.

A partir de esta consideración entendemos que la disposición de las fuentes en el volumen analizado (archivo), en una operatoria discursiva de reconstrucción a partir del extracto de versiones segmentadas y contrapuntos dialógicos, evidencia un discurso que remeda la polifonía y su circulación entre los pliegues de la historia. Por lo tanto, leer los archivos como monumentos - nos referimos al acto de lectura gestionado en ese dispositivo de historia oral que comprende La noche de Tlatelolco - implica resignificarlos.

\section{Consideraciones finales: la construcción de una pos-memoria}

La memoria define en el relato un espacio de construcción donde las voces que testimonian participan de un modo colectivo. Sus limitaciones, contradicciones, incompletud, simplificación, evasión, miedo, reticencias - es decir, el olvido o recuerdo fragmentado reorganizan la tensión entre verdad y posmemoria frente los acontecimientos. Ante el silencio que ha producido la violencia extrema, la falibilidad de la memoria abordada desde el relato emerge en su doble dimensión ética y estética. En este punto, la autoridad del testigo se torna clave porque es necesario considerar el problema del impacto del trauma, la ruptura del sentido, la temporalidad y los desplazamientos - y no transparencia - de la memoria. Por lo tanto, los límites y potencialidades del testimonio forman parte del mecanismo de la memoria que se 


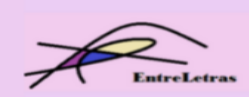

REVISTA ENTRELETRAS (ARAGUAÍNA), V. 12, N. 3, SET./DEZ. 2021 (ISSN 2179-3948 - ONLINE)

activa dentro del relato. Allí es posible advertir entonces una clara postura ética vinculada a la responsabilidad hacia el otro: la víctima.

En suma, relacionado con la pluralidad de voces observamos el intento por desarticular las trampas de la memoria. Por consiguiente, eludir/elidir sus olvidos, huecos, lagunas, contradicciones, silencios y distorsiones se transforma en el continuo eje de reorganización del relato/enunciado. Se trata así de evitar la dicotomía entre la sacralización y la banalización de la memoria para alcanzar una perspectiva que asuma con rigor analítico los acontecimientos medidos en su condición de trauma sobre la memoria colectiva. En este sentido, la verdad surge como una noción compleja que atraviesa diferentes campos del saber:

\footnotetext{
No se trata de liberar la verdad de todo sistema de poder - esto sería una quimera, ya que la verdad es ella misma poder-sino de separar el poder de la verdad de las formas de hegemonía (sociales, económicas, culturales) en el interior de las cuales funciona por el momento. La cuestión política, no es el error, la ilusión, la conciencia alienada o la ideología: es la verdad misma. (FOUCAULT, 1992, p. 189)
}

Allí, la política, lo jurídico y lo histórico-social conforman el entramado del relato/enunciado que se construye sin distancia histórica y en un intento por deconstruir los usos políticos de la memoria. Dichos usos evidencian como sustrato la coerción simbólica sobre los cuerpos de los que ofrecen testimonios.

\section{Referencias}

BASILE, Teresa. (Coord.). Literatura y violencia en la narrativa latinoamericana reciente. La Plata: Universidad Nacional de La Plata, 2015.

FABER, Sebastian. Actos afiliativos y postmemoria: asuntos pendientes. Pasavento: revista de estudios hispánicos. vol. 2, n. 1, p. 137-156, 2014.

FOUCAULT, Michel. La arqueología del saber. Buenos Aires: Siglo XXI, 2002.

FOUCAULT, Michel. Contestación al círculo de Epistemología. In: El discurso del poder. Buenos Aires, Folios, 1993.

FOUCAULT, Michel. El orden discurso. Buenos Aires: Tusquets, 2005.

FOUCAULT, Michel. Microfísica del poder. Madrid: La Piqueta,1992.

GENSCHOW, K y Spiller, R. Trauma colectivo y (post)memoria audiovisual en América Latina del siglo XXI. Iberoamericana, XVII, n. 65, p. 11-16, 2017.

LÓPEZ BADANO, Cecilia y Linet CUMS YUMAR, Dictadura, memoria y literatura: las variaciones simbólicas del trauma. Caderno de Letras, n. 37, p. 121-131, maio-agosto, 2020. 


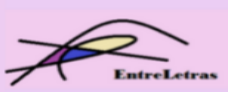

REVISTA ENTRELETRAS (ARAGUAÍNA), V. 12, N. 3, SET./DEZ. 2021 (ISSN 2179-3948 - ONLINE)

O’DONOGHUE, Samuel. Posmemoria y trauma: algunos problemas teóricos y sus consecuencias para la crítica literaria. Pasajes. n. 56, pp. 8-25, 2019.

PONIATOWSKA, Elena. La noche de Tlatelolco. México: Era, 1971.

Recebido em 16 de novembro de 2021. Aceito em 05 de janeiro de 2022. 